Integrated practice in the early years in Australia: The assumptions, omissions and contradictions of policy reform

\begin{abstract}
The aim of this paper is to examine current national early years' policy reform which emphasises the importance of service integration, national quality standards and a quality knowledge base for educators concerning the provision of early childhood education and care. Using Queensland, Australia as an example, a policy discourse analysis undertaken identifies two problematics of implementing current national policy - the early childhood education and care problematic and the integration problematic. The paper argues that speedy implementation of a national policy in order to meet national targets, has unintended consequences for the knowledge base of educators, and the possibility of collaboration within service provision. Although government commitment in this area is evident, these consequences and the current (im) possibility of integration are the result of the lack of a specific integration strategy, and government investment focused on the development of an integrated workforce.
\end{abstract}

\title{
Keywords
}

Integration, transdisciplinary, early childhood education and care, assumptions, omissions, contradictions 


\section{Integrated practice in the early years in Australia: The assumptions, omissions and contradictions of policy reform}

\section{Introduction}

The field of early childhood education and care (ECEC) in Australia has always been a complex one. This complexity is compounded by the fact that each state and territory has its own regulations and approaches to how the field is governed and also to how certain practices are enacted. This situation has caused fragmentation that has often led to division between those who work in the sector. Such fragmentation has been longstanding and has led to many significant and somewhat inequitable changes to policy and practice. Thus, it is difficult when engaging educators from ECEC in any discussion or debate, to always expect aligned approaches to particular issues and problems (name deleted to maintain the integrity of the review process).

This situation has become more problematic in recent times, as the Australian government has implemented policy that privileges integrated practice in the early years (Commonwealth of Australia, 2009). This type of practice calls for professionals of different disciplines to work together, often in one setting, to deliver programs of care, education and early intervention and prevention to young children and their families. This practice may be considered enriching in many respects, for example diverse opinions might lead to more complete information about children and families. 
However, in a sector so fragmented as the ECEC sector in Australia, such practice can also be highly problematic.

This notion of inter-professional practice and integration of services came to prominence in 2003 when the UK government introduced a Green Paper entitled Every Child Matters (Crown Copyright, 2003). This legislation was introduced following a public outcry resulting from the death of Victoria Climbie, a young girl tortured and abused by her great aunt and the man with whom they lived. Via this Green Paper and the subsequent Children Act 2004, the UK government sought to improve services for children and families by focussing on early intervention and prevention programs which included universal and targeted integrated frontline delivery. For the UK government, this integrated delivery would include certain elements such as, a common assessment framework that included a shared language about children and young people and information sharing across services. The main aim was to ensure that health services worked more effectively with other children's services and schools.

This model of integrated practice was underpinned by a very solid framework with outcomes for children and families at the centre. The notion of integrated front line delivery was backed up by a whole-of-system change that included integrated processes (previously mentioned), integrated strategy and inter-agency governance. The delivery of these integrated frontline services was centred in the Sure Start Children's Centres, managed by local authorities with a view to allowing the centres to partner with 
statutory and voluntary organisations. Children's centres were to be 'models of integrated service provision where primary care trusts, LAs, JobCentre Plus, education and child care providers, social services and community and voluntary agencies work together to deliver seamless and holistic services' (Crown Copyright, 2003).

These Children's Centres were to work as integrated hubs for the local community by 'bringing together a range of services, usually under one roof, whose practitioners then work in a multi-agency way to deliver integrated support to children and families' (Children's Workforce Development Council, 2010, np). These services were to have a common location, in this case the children's centre, share a common philosophy, vision and agreed principles for working with children and families. In fact, these notions, a common philosophy, vision and agreed principles for working with children and families, are at the heart of the definition of integrated practice utilised in the Sure Start program.

It is this common philosophy and vision and agreed principles for working, which is most important here. Since this paper has been written, the Sure Start Model has been broken apart in many ways by different UK governments, most particularly, the current government. All the changes various governments made were likely undertaken with the best intentions. Regardless, what was significant about the initial implementation of the Sure Start Model was the agreed framework of practice across disciplines including this common philosophy and vision and integrated delivery of 
services via the Early Excellence centres. It was this framework that gave this model its best opportunity for success and indeed there is evidence that success did occur.

While this idea of integrated ECEC practice in Australia has been adopted from the UK model, a different approach to its implementation has been utilised. The Australian model has not been underpinned by a strong practice framework and does not have a uniform point of delivery. This different approach has led to unintended consequences, which have impacted on the way integrated practice has been understood and designed in Australia. While the policy relating to integrated practice seeks to affirm these initiatives, practice 'in the real' (Foucault, 1981, p. 13) does not reach these standards. Practice does not represent an integrated approach with a focus on interprofessional work where professionals interact around particular cases rather than working in isolation.

\begin{abstract}
Aims and scope
This paper examines the introduction of this recent government policy on integrated ECEC practice and also its current impact on the ECEC sector in Australia. To do so, the authors undertake a policy discourse analysis as a means of challenging particular philosophical approaches to ECEC practice and the policy moves to integrated practice. Thus, the authors seek to create a space of interrogation (Elwick, 2010), which provides possibilities for looking beyond reductive concepts and habitual
\end{abstract}


ways of thinking (Elwick, 2010) in order to consider how practice might be otherwise (Foucault, 1984).

Borrowing from Popkewitz and Lindblad (2000) and (name deleted to maintain the integrity of the review process), the paper takes the form of a discursive policy analysis and cross-disciplinary literature review. Such an approach enables the examination of the assumptions, omissions and contradictions (Bowe, Ball and Gold, 1992) in current ECEC policy direction, which will highlight consequences for the ECEC sector. This approach will also demonstrate how integrated ECEC practice in Australia is neither possible nor impossible at this particular historical time and the impact this uncertainty has on the contemporary ECEC knowledge base.

Situating this investigation as problematic allows for the application of critical social theory as a framework for analysis. Such a framework enables the policy examination and implementation to be opened up for scrutiny in ways that allow marginalised perspectives to be made evident as contradictions are brought into focus. This means that new understanding of consequences for children, families and professionals can be highlighted.

What remains unsaid at this point however, is what would integrated practice in the early years in Australia actually look like given the lack of a common philosophy, vision and agreed principles for working, a common practice framework and a uniform point of delivery? Surprisingly, in Australia some instances of such practice are 
occurring in Early Years Centres across the country. The Queensland government's Early Years Centres, which are run by a variety of non-government organisations, are engaging in integrated practice - that is, for the purposes of this paper - in interprofessional practice and integrated service delivery. These centres are providing early intervention and prevention health and well being programs for families in particular place-based settings across the state. Alongside these early intervention and prevention programs, child care programs are being run. Practice in these centres is integrated as the centres deliver universal and targeted soft entry programs, which are accessible to any family in the region. Via the delivery of these programs, families can explore options for or be referred to, other health and community based services contained within the Early Years Centres or in other non-government organisations. However, although these centres, which are closer to those in the Sure Start model, are running successfully, they are yet to bridge a variety of issues. Such issues include: disparity between federal and state government laws, the erosion of the early years knowledge base, the inadequate preparation of early years teachers, the care and education dichotomy, inequitable pay conditions, an inherited silo mentality and confusion relating to different definitions and terms. These issues will be discussed in what follows. 


\section{ECEC practice in Australia}

In ECEC in Australia, practice is implemented largely across the health, education and community services sectors. Within these sectors, silos of practice exist (Press and Woodrow, 2005), which restrict the opportunities for knowledge exchange, create duplication of services and contribute to increased costs (name deleted to maintain the integrity of the review process). Moreover, lack of knowledge exchange means that new ideas and approaches in particular sectors are often not understood in others, thereby increasing protectiveness of individual knowledge bases and fostering suspicion that decisions about particular practice approaches are not evidence-based (Cheeseman, 2007). Such factors undermine, rather than enhance possibilities for knowledge sharing and exchange, break down possibilities for successful integration of services and also result in less inclusive practices in work with young children and their families (name deleted to maintain the integrity of the review process).

It is amidst this fragmentation that the current federal government legislation has been introduced. The Rudd Labor Government's National Early Years Reform Agenda has a key focus for all Australian children to 'have access to high quality early learning and care' (Rudd and Maklin, 2007), which has placed ECEC at the forefront of the Council of Australian Governments (COAG) agenda since 2007. A National Early Years Learning Framework was developed as a response to COAG concerns to address the issue of quality ECEC across Australia. This framework is to be used by all 
educators and professionals working with young children, regardless of the context, to build greater continuity in the approach to early years learning and development. The first assumption of this policy (Bowe et al, 1992) then is that there is a consolidated and agreed knowledge-base across sectors.

Additionally, as previously mentioned, integrated practice focussing on interprofessional work in the early years has become an important reform topic in recent times. Specifically, past documents such as the Starting Strong II report (Organisation for Economic Cooperation and Development (OECD), 2006), the Stronger Families and Communities Strategy (Department of Families, Communities and Indigenous Affairs, 2004), the Best Start report (Raban et al., 2006) and the Towards an Early Years Strategy (Department of Communities, Disability Services and Seniors Queensland, 2006), have all pointed to the need for early years' professionals to be prepared to work in integrated settings. Additionally, more recently such practice has been endorsed nationally in Investing in the Early Years - A National Early Childhood Development Strategy (Commonwealth of Australia, 2009) and Supporting the Development of Young Children in Australia: 2009: A Snapshot (Department of Education, Employment and Workplace Relations (DEEWR), 2009a). These initiatives and reports seek to inform universities and other tertiary institutions that present ECEC preparation programs do not extend to preparing prospective educators and professionals to work in such integrated settings (Commonwealth of Australia, 2009; 
Department of Communities, Disability Services and Seniors Queensland, 2006; Elliott, 2006; OECD, 2006). In fact, there is, at present, little real focus on how to prepare educators and professionals for these integrated practice settings in higher education programs, particularly at the undergraduate level or indeed, in terms of the pathways into such programs (Sims, 2010).

Moreover, it is important to note that the Investing in the Early Years Document introduced in 2009 is the last official government policy document that focuses on integrated practice. This document was meant to influence practice in this area until 2020 and yet no other government policy referring to these notions has been written since. At this stage, the recent change of government in Australia has not indicated any alterations to this policy, which originally had bipartisan support via COAG (2009).

The government focus on the introduction of early years' integrated practice and on high quality early learning and care is further complicated by the fact that each state in Australia has its own legislation surrounding ECEC programs. Moreover, the fact that comprehensive and complex legislation is now being implemented in an already contentious space, means that many consequences both intended and unintended are already present. The second assumption of these policies (Bowe et al, 1992) is that it is possible for federal policy to be seamlessly implemented in an environment where multiple legislative requirements are present. Such an assumption merely exacerbates the complexity of the implementation of this policy reform. 
To navigate and account for the complexity of this policy environment and the environment where the policy is being implemented this paper examines the implementation of government policy on early years integrated practice according to two problematics - the ECEC philosophy problematic and the integration problematic. These two problematics are used to highlight how such a policy environment leads to the previously mentioned intended and unintended consequences for all stakeholders in the ECEC sector.

\section{The ECEC philosophy problematic - A one state example}

One of the ways in which ECEC policy reforms can be examined is by considering this sector in an individual state in Australia. To do so, the authors of this paper have chosen the state of Queensland. The reason for this choice lies in the fact that arguably, it is in Queensland where the most stark differences and constraints are being experienced. Thus, by considering the impact of these differences and constraints in this state, a picture of the assumptions, omissions and contradictions (Bowe, et al. 1992) of early years policy implementation in Australia can be opened up for scrutiny.

In recent years the ECEC field in Queensland, Australia has negotiated significant change. In fact, it is in Queensland where some of the divisions between educators in ECEC have been most strongly highlighted. As early as 1988, Petrie explored the notion of the care and education dichotomy that was dividing the ECEC 
sector, arguing for a more streamlined approach to practice. In the years since this paper, this dichotomy still exists in Queensland, (name deleted to maintain the integrity of the review process). Alison Elliott (2006) attests to this point stating that, recent funding shifts have widened the care/education dichotomy (name deleted to maintain the integrity of the review process). Elliott (2006) states, 'The funding shift from "education" to "care" without also providing strong developmental and learning programs in child care centres has widened the care-education divide and disadvantaged countless children' (p. 11).

While most ECEC educators would undoubtedly welcome the recent state and federal government attention to the importance of the early years in policy formulation, governments are still designing policy in line with the care and education dichotomy (name deleted to maintain the integrity of the review process). For example, in Queensland in 2008, announcements by the then Premier of Queensland, the Honourable Anna Bligh, only added to this dichotomy. The new policy direction at that time separated care and education for $0-5$ year olds by establishing more educational sites for 3-4 year olds in the form of 240 extra kindergartens (limited hours settings) across the state. In the Toward Queensland 2 policy release (Department of Education and Training (DET), 2008), the Premier announced that younger children would now have access to better early years' services by the Queensland government and the Federal government supporting child care centres to provide 'better' early childhood 
education, for 3-4 year old children (name deleted to maintain the integrity of the review process).

This government investment highlighted the difference between those children who are "entitled to education" and those who are "entitled to care" For example, in 2008, the government's own figures stated that of the 53,000 3-4 year old children in Queensland, only 12,000 attend an early childhood centre where a qualified teacher delivers 'a recognised education program' (DET, 2008, np). Only 10 per cent of the 29,000 who attend child care centres were able to access to 'an education program delivered by a qualified teacher' (DET, 2008, np). To address this issue, the Queensland government was to spend 300 million dollars building new 'extended' kindergartens for 3-4 year olds and make further funds available to provide 'support' to the child care centres currently 'offering a valuable service' for working families. Thus, in the Premier's terms child care centres provide a 'service', while kindergartens provide 'better' early childhood education (DET, 2008, np). Such thinking represents the third assumption of both Queensland and Federal government policy (Bowe et al, 1992) that care and education are different and not therefore inextricably linked. This thinking also means a contradiction in policy (Bowe et al, 1992) as care and education are treated as silos rather than understanding these disciplines as integral to each other.

Such notions are challenging for the ECEC sector on two fronts. First, the different legislation in each state means that states like Queensland are lagging behind 
as mentioned above. Although the figures relating to access for 3-4 year olds to an Early Childhood Education teacher have improved since 2008, they are still low compared to other states. This means that the Queensland government has a significant task in front of it if federal government targets of access to quality childhood education for 15 hours a week for 40 weeks a year, one year prior to school for all children are to be reached by 2014 (Commonwealth of Australia, 2009; DEEWR, 2009b). Consequently, the Queensland government is doing all it can to encourage teachers into early childhood education to meet this demand. For example, this government has currently a plan in place, entitled the Early Childhood Education and Care Workforce Action plan 20112014, which represents an investment of over \$76 million in the ECEC workforce in order to meet the new federal government targets (Department of Employment Education and Training, 2011).

The second problem is that some of the strategies the Queensland government is implementing were questionable from the perspective of contemporary early years practice, and do not ensure the strongest knowledge base with a value for service integration. One such example exists in a thirty-six week TAFE bridging course being offered to teachers so that they can 'add' early childhood to their repertoire (see http://coursesearch.bn.tafe.qld.gov.au/tafe/training/CHC30712_Certificate_III_in_Child ren_s_Services/Brochure_Q520.ashx). Completion of the stated program would allow individuals' registered as a teacher with the Queensland College of Teachers prior to 
December 2011 to hold employment as a kindergarten teacher in care centres. The inference of such a program is that early years teachers do not need many additional skills that require longer periods of study. The suggestion that a thirty-six week course, with no emphasis on service integration, is enough to re-train primary and secondary teachers indicates that early childhood expertise can be obtained by a short, sharp addon. This is the second contradiction of government policy (Bowe et al, 1992) considering the value the federal government is placing on all 3-4 year old children having access to 'quality play-based early childhood education' by a university educated early years professional (DEEWR, 2009b). While most early childhood teachers train for four years in order to specialise in this discipline, it is now maintained (via this bridging program) that a 6 month add on to any other teaching program is sufficient to produce a university qualified early years teacher.

This notion is highly concerning for the early years' sector as it diminishes the value of the expertise of the early childhood teacher. This inequitable situation that exists in Queensland has been historically constituted and embedded in policy as a result of many somewhat unrelated but important historical events. One such event occurred in 1996, when the Queensland Industrial Relations Commission (QIRC) handed down a landmark decision that was to have a significant impact on the childcare field in Queensland (name deleted to maintain the integrity of the review process). This decision included a claim that early childhood teachers working in day care should 
receive pay parity with teachers in other sectors. During these hearings this claim eventually focussed on one issue; whether teachers employed in day-care centres were actually teaching (name deleted to maintain the integrity of the review process). The decision was that teachers in day care were not teaching - they were merely providing a developmental program. Such a move meant that as a developmental program required 'less' skill, these teachers did not 'deserve' pay parity (Burton and Lyons, 2000). The Industrial Court endorsed a discursive shift that instituted a demarcation between education and development (name deleted to maintain the integrity of the review process). Education was clearly more worthwhile and those who provided education were worth more fiscally (name deleted to maintain the integrity of the review process).

During the court case, private long day care providers argued against the pay claim (Burton and Lyons, 2000). These arguments centred on the fact that when a qualified teacher was not required to provide an educational program, then they were not entitled to pay parity for such a program. Significantly, one employers' organisation argued:

If Teachers $[s i c]$ are to have a significant place in childcare it needs to be on the basis that they are doing something conceptually and identifiably different to other childcare workers. If this is not the case and the view is maintained that they do the same thing as other workers only a whole lot better, then the simple reality is that the childcare industry does not, in most 
cases, want or need what they have to offer (Local Government Association final submission, QIRC, 1996, p. 11, cited in Burton and Lyons, 2000).

This particular industrial position, that is still part of law in Queensland, endorsed the divide between care and education, making it very difficult for care to be considered as significant as education. This industrial position has impacted on all involved in ECEC in this state, as other policy and industrial decisions that have followed it, have continued to endorse the notion that education matters more than care. This endorsement has also led to the idea that education is conducted in more formalised environments and that informal environments represent care and so cannot include education. This issue represents both a further assumption and contradiction (Bowe et al, 1992) of the Early Years Reform Agenda and its focus on integrated practice. This Agenda assumes that the policy in relation to making teachers available to 3-4 year olds will transfer easily to all states. However, this legislation in Queensland means that teachers delivering this program in this state will not receive pay parity or as it happens, the same recreation leave as teachers in other sectors as the Queensland situation does not make room for this possibility. This begs the question - how will such teachers be retained in the sector? Furthermore, another contradiction in policy is evident. If care and education are different as they clearly are in this Queensland policy, then the practice undertaken in these sectors cannot as easily be integrated as if they 
were considered to be inextricably linked. At this point then, the aspect of the new Federal government's Early Years Reform Agenda relating to universal access to an early childhood teacher for 3-4 year olds has not meant a change to this Queensland decision. This means that a high level of uncertainty remains a consequence within the sector in this state and possibilities for teacher retention in child care are minimised.

In Queensland, the ECEC sector has a history of turmoil and this turmoil is not being reduced by government policies that privilege education over care. While there would be few early childhood teachers who would not applaud the new federal universal access legislation, policy decisions, such as those previously mentioned, are particularly problematic for these same teachers. While the ECEC sector in Australia accepts such policy decisions as those relating to the thirty-six week bridging courses being implemented in Queensland, then this sector is allowing the integrity of the knowledge base of early childhood to be eroded by its own fragmentation. This is an unintended consequence of the Early Years Reform Agenda and once again a contradiction in policy (Bowe et al, 1992) as it fosters an erosion of the base it is intending to protect.

The contemporary early years knowledge base is underpinned by multiple theoretical approaches such as that of Vygotsky, Rogoff and Malaguzzi, which view children holistically, as capable and independent learners who learn best when they are actively involved in negotiating their own learning, and exploring their own interests 
(Arthur et al., 2012; Grieshaber and Canella, 2001; Hutchins and Sims, 1999). This view of young children is not widely endorsed by other sectors, including the larger education sector, where approaches to learning are often more compartmentalised and structured. The policy decisions being made in Queensland, in an effort to meet federal government targets (that is before 2014 all children have access to a highly qualified early childhood educator for 15 hours a week, for 40 weeks a year during the year prior to school (Commonwealth of Australia, 2009; DEEWR, 2009b) are being made quickly as necessitated by these aforementioned targets. This speedy implementation is encouraging the afore-mentioned unintended consequences, which are undermining the possibility of privileging holistic strength-based views of children and childhood, which the ECEC sector provides and holds as integral to their practice.

A federal policy such as the Early Years Reform Agenda becomes problematic as differences between states in training, definitions of, and settings of practice for kindergarten teachers are obvious. While it could be argued that such a situation may only impact on Queenslanders, other states are not immune from such anomalies. In Queensland kindergarten teachers work in kindergartens, schools and child care centres, and are four year trained by education faculties. While in Victoria for example, kindergarten teachers are three year or four year trained by education faculties and work in kindergartens and child care centres but not necessarily in schools, depending on where they are trained. Uniformity of practice is significantly difficult when terms have 
different meanings in different locations. For a sector already complicated by a care/education dichotomy, the differences exacerbated by policies like the Early Years Reform Agenda contribute to the many afore-mentioned assumptions and contradictions, which work to break down unity and fragment and not integrate practice in the sector.

In Moss's (2006) terms a move to situate early childhood teachers firmly within the child care arena disrupts current child care discourses. This move is disruptive as attempts to align the pedagogic and child care discourses (Moss, 2006), try and close the 'widening care-education divide' (Elliot, 2006, 14). To attempt such a move on this ECEC field at the moment is both enabling and constraining (Foucault, 1980). Moss (2006) states that similar competition between early childhood education pedagogic discourses and child care discourses are complicating the sector in the UK. Such a position is replicated and intensified in Australia, where reforms do not have a solid infrastructure as they did in the UK, are moving quickly and where the care/education dichotomy is growing and not shrinking (Elliot, 2006), in relation to such reforms. What is most apparent is that unless the complexities that some of these policy initiatives create are fully understood and accommodated, then it is likely that new and exciting opportunities will only be achieved for a few.

What can be seen from this examination of the care/education problematic is that in countries like Australia where each state and territory has its own regulations and 
laws, the implementation of federal government policy is highly problematic. Such a situation highlights how assumptions, omissions and contradictions in policy implementation and reform (Bowe et al, 1992) occur and remain in place regardless of how policy is enacted. This situation also points to the fact that although certain policy initiatives such as the move to integrated practice might be in place, their implementation is both possible and impossible as unintended consequences of policy implementation are still present. While these unintended consequences such as the disparity between federal and state government laws, the erosion of the early years knowledge base, the inadequate preparation of early years teachers, the care and education dichotomy, the inequitable pay conditions, an inherited silo mentality and confusion relating to different definitions and terms, are present, then integration becomes impossible and practice will continue to be siloed. Developing an understanding of the training requirements, remuneration and settings of practice for early childhood educators within each state, and outlining a step by step process towards service integration, and the meeting of national quality standards for each state, can aid in the implementation of this federal government policy and make integrated practice more likely. 


\section{The integration problematic}

The notion of integrated practice in ECEC, which is currently being promoted in Australia, is being used to encourage government and non-government organisations to work together in order that parents and children are provided with seamless service delivery and practice. Integrated practice is intended to be transdisciplinary, where professionals focus on inquiry rather than disciplines. Transdisciplinarity goes beyond multidisciplinarity and interdisciplinarity as it seeks to deal with the supercomplexity of family situations by placing the family and its issues and not the discipline at the centre of practice. In Australia, integrated practice is not necessarily being promoted as transdisciplinary and so no infrastructure to support this notion is being established. Thus, integrated practice in Australia is still being implemented in a siloed way, with the focus on particular disciplines rather than on particular practices.

In the case of ECEC integrated practice, there is a risk that this method of implementation that focuses on disciplines privileges the knowledge bases of more 'powerful' disciplines. Therefore, it is likely that the implementation of integrated practice in Australia allows for an acknowledgement of the health and community services focus of this type of practice but that the ECEC focus can be somewhat overlooked. ECEC practice in integrated settings can be viewed through a health or community services lens. This means that the contemporary ECEC knowledge base one that is strengths-based, holistic, child centred and driven and underpinned by 
childhood competence - can be marginalised or not considered at all. Such an omission (Bowe et al, 1992) has significant consequences for ECEC professionals and for children and families and so this omission needs to be addressed in policy reform.

Addressing this omission is difficult while there is a sense that care and education are somewhat divided. While this understanding continues, health and community services professionals are more likely to see their task as relating to care, while their perspective of early childhood care and education is as part of education (Author's Own, 2010) This is problematic for early childhood care and education professionals who sit 'in between' these two sectors. It is possible that attempts by such professionals to engage in integrated practice will be thwarted, as they may not be considered part of health or community services but as situated in education and thus, their perspectives relating to health and community service program delivery may be considered irrelevant.

\section{Integration in Australia}

In 2004, the Australian Government introduced the Stronger Families and Communities Initiative. Underpinned by the work undertaken in the UK around the establishment of Sure Start, which endorsed the notion of integrated practice, this initiative was designed to give children, families and communities the opportunity 'to build a better future' (Department of Families, Communities and Indigenous Affairs, 
2004). John Howard's Liberal government, via the Department of Families, Communities and Indigenous Affairs, funded particular non-government organisations to lead community development and capacity building in certain designated communities (name deleted to maintain the integrity of the review process). The Stronger Families and Communities Strategy sought to encourage a collaborative approach to community development, understanding that solutions to community issues are manifested through the efforts, resources and assets located within various settings including community services, health, education and childcare centres. Thus, the initiative sought to align these community development strategies with the knowledge base of ECEC (name deleted to maintain the integrity of the review process).

The Stronger Families and Communities Strategy was introduced as a result of Australian and international evidence that confirmed that the early years of a child's life were critical to future development, particularly as it is the period of rapid brain growth and development (Mustard, 2001). Moreover, it was highlighted that it is during this period of life when the 'foundations for learning, behaviour and health over the life course are set' (Department of Families, Communities and Indigenous Affairs, 2004, np). The centre-piece of this Stronger Families and Communities Strategy was the Communities for Children (CfC) project. The government positioned this program as a 'new and innovative approach to policy development and service delivery' (Department of Families, Communities and Indigenous Affairs 2004, np). It was via this program 
that the government intended to implement local strategies that '[were] grounded in evidence about what works best to support early childhood development' (Department of Families, Communities and Indigenous Affairs, 2004, np).

The Stronger Families and Communities Initiative was originally funded with $\$ 142$ million dollars, part of which was used to fund the Communities for Children Project. Under the CfC project, non-government organisations were funded as Facilitating Partners (FPs) in specific regions to oversee the development of a Community Strategic Plan (CSP) and a Service Delivery Plan (SDP) for the region. Each Facilitating Partner organised, in consultation with the local community, their own CSP and SDP for the region, to be approved by the Department of Families, Communities and Indigenous Affairs. FPs were selected by tender and, while the brief of the Australian Government was to deliver services that aligned community development strategies with the knowledge base of ECEC, there was no clear definition about how this alignment was to occur. Moreover, there was no requirement that the FP employ managers or workers who were able to understand and articulate both the community development and early years' knowledge bases. Such a situation represents an omission in policy (Bowe et al, 1992) as there has been no effort to ensure an agreed upon approach to early years care and education and no official instruction or in service about how to engage in inter-professional practice and integrated service delivery. 
The CfC projects were funded from 2006-2009. Following the election of the Rudd Labor government in 2007, the Stronger Families and Communities Initiative was re-invented becoming the Family Support program and the CfC projects were re-funded in some cases and extended. In the Rudd program, the focus shifted more strongly towards targeted rather than universal services. While the term 'integrated' is not specifically used, one of the main aims of the program is more flexible and responsive services that families can 'more easily enter and move between...reducing the silos that were evident in the previous structure' (Department of Families, Housing, Community Services and Indigenous Affairs, 2009, np). Thus, the notion of 'intensive and coordinated support' is still very much a focus of practice and has been further endorsed by the Gillard government. It is yet to be seen how the current federal government responds to this policy but initial indications are that the $\mathrm{CfC}$ programs will be extended.

In the UK model, the notion of integration is situated, legislated and resourced with infrastructure according to a specific framework of integrated practice while, in Australia, the Family Support program has no underlying inter-professional philosophy or infrastructure that supports such a model. Second, the Australian model also separates education and care and has no focussed approach in child care, preferring to fund programs in child care centres in an ad hoc way. 
Additionally, the Australian model relies on implementation via nongovernment organisations. The participation of government organisations is again, somewhat ad hoc and determined by understandings of the term 'integrated' and how this notion links to multi-disciplinary and non-siloed practice. This means that government and non-government organisations have no shared philosophy, vision, language or intent in relation to how integrated practice might be implemented. Interprofessional practice occurs largely through the good will of those involved and the willingness of individuals to seek out ways of engaging via a shared vision and language, which is informed by all partners. Consequently, there is no real incentive for professionals, who consider their knowledge base powerful and evidence-based, to break out of silos to consider other perspectives. This situation has particular implications for early years' teachers and educators, particularly those with lower levels of training. The question of 'who leads' in integrated and inter-professional contexts is contested and 'up for grabs'. While the ECEC sector is discussing 'what' needs to be included in pre-service early childhood education programs (Sims, 2010), leadership roles in integrated settings are being decided in a siloed way, with more 'powerful' knowledge bases such as those in health, being privileged in this respect.

However, a recent Commonwealth of Australia (2009) policy document entitled Investing in the Early Years - A National Early Childhood Development Strategy has a much more specific approach to the notion of integrated practice. Based on an 
ecological model (Commonwealth of Australia, 2009, p. 15) the document suggests 'integrated early childhood development services and [a] support delivery model' (Commonwealth of Australia 2009, p. 19). However, the definition of an integrated model in this document appears to be related to the delivery of services and not the way that practice is implemented. In this document 'an integrated model' is defined as a combination of intensive, targeted and universal services (Commonwealth of Australia, 2009, p. 19). The document highlights the importance of building partnerships with Non-Government Organisations (NGOs) and employers and also signifies the importance of 'establishing clear and accessible referral pathways between universal to targeted and intensive services...building the evidence base about integrated service delivery models' (Commonwealth of Australia, 2009, p. 27). It does not, at any time, promote the notion of 'integrated practice' as involving a more interdisciplinary (where a group of allied professionals work together to support children and families from their own disciplinary perspective) or transdisciplinary (where a group of allied professionals work together by moving beyond their discipline to a new space of practice that provides more seamless program delivery) approach, which is in contrast to policy in the UK. While the notion of a more cohesive approach is implied in the Australian document, there is not the strong focus on multi-agency practice or governance as such and there is certainly no funding to support necessary infrastructure relating to such practice. The omission in this policy (Bowe et al, 1992) is the lack of some further 
information of how to engage in inter-professional practice and integrated service delivery. It is assumed (Bowe et al, 1992) professionals know how to collaborate and that integrated service delivery will occur simply by co-locating services or by centring program delivery in one service, which has the responsibility to broker to other organisations. It is also assumed that funds for in-servicing and extra resources will not be required.

Such discussion is not meant to suggest that there is not funding to change the way in which early years' services are delivered. As previously mentioned, funding is available from the federal and from some state governments for NGOs to set up Early Years Centres. These Centres are run with a focus on integrated service delivery and also on integrated practice. One such centre funded by the Queensland government has recently opened in Logan City in Queensland. The centre is intended to provide a range of 'integrated parenting and family support services such as family day care, playgroups, child health and development and parenting support, health screening access to immunisations and pre and post-natal care' (see http://www.benevolent.org.au/). While there appears to be a strong focus at this new centre on integrating with local service providers and partner agencies, the brief from government is that the centre acts as a 'one stop shop' (see http://deta.qld.gov.au/early childhood/families/early-years-centres.html), with multiple services and staff available. The omission in the policy (Bowe et al, 1992) underpinning these services is that there 
is no specific government brief on how these services are to be led or how the staff are to practice. It would appear that these notions are largely at the discretion of the sponsoring agency and the staff that they employ. A breaking down of silos happens serendipitously or by accident (Foucault, 1980) as it relies purely on the way in which particular individuals and organisations interpret how integrated practice will happen 'in the real' (Foucault, 1981, p. 13)

There is a plethora of research (Moore, 2008) relating to how this notion of integrated practice actually works, with suggestions that such practice does not merely 'happen' by osmosis, co-location or even policy direction. Moore and Skinner (2010) state that effective integration requires four levels of practice. These include policy integration across governments, local integration of planning, service delivery integration and integration of teams and professional roles. Therefore, what is evident with respect to Australian policy is that such policy relating to integration of services and inter-professional practice contains many assumptions, omissions and contradictions (Bowe, Ball and Gold, 1992), which create confusion about how policy is enacted 'in the real' (Foucault, 1981, p. 13). Thus, while such elements as information sharing and common assessment frameworks (Sims, 2010) might lead to improvements in early years practice, these elements do not ensure integrated practice, nor do they clearly indicate whose practice and knowledge base is privileged to lead implementation in such settings. 
Viewed in this way, the intention of policy can be open to interpretation, and the objectives misrecognised (name deleted to maintain the integrity of the review process) or misunderstood. The authors of this paper suggest that this is the case with current early years' policy in Australia. The suggestion is that these notions of integration and inter-professional practice are not clear, understood nor agreed upon at this point in time. Furthermore, it can be argued that such terms are being misrepresented, misused and misinterpreted. For example confusion continues in relation to the term 'integrated' and this situation is unlikely to change. Moreover, terms like inter-professional, multidisciplinary, inter-disciplinary and transdisciplinary are being used sometimes, interchangeably, to describe the notion of integrated practice. However, these terms all mean something different with respect to practice. Nevertheless, it is the definition of these terms and their application that the possibility for an enhanced level of practice might be found.

This situation exists because of the assumptions, omissions and contradictions mentioned earlier. In relation to the ECEC philosophy problematic these assumptions omissions and contradictions include: disparity between federal and state government laws, the erosion of the early years knowledge base, the inadequate preparation of early years teachers, the care and education dichotomy, the inequitable pay conditions, an inherited silo mentality and confusion relating to different definitions and terms. In relation to the integration problematic outstanding policy omissions are that there is no 
agreed upon knowledge base for the delivery of early childhood education and care services and no infrastructure around in service training about how to engage in integrated service delivery or inter-professional practice. The assumption here is that professionals know how to collaborate and so inter-professional practice will simply occur. There is also no official government brief on how integrated service delivery will actually occur. Therefore, it is evident that policy reforms relating to integrated practice are likely to be unsuccessful if these assumptions, omissions and contradictions are not addressed. Instead of providing children and families with a seamless delivery of services, in many instances claims about integrated practice will remain unrealised. This notion will continue to be both possible and impossible instead of enhancing practice and building capacity in the early years.

\section{Conclusion}

The examination of these integration and ECEC philosophy problematics has highlighted how the notion of integration, although mandated in Australian government policy is both possible and impossible in practice. The examination points to a lack of an integration strategy, which would work to outline the steps necessary for collaboration and integration, and facilitate its achievement. While the federal Australian government intention in this policy may indeed be genuine, the financial commitment is lacking. The Australian government has not invested in preparing its 
workforce for the introduction of this policy, the infrastructure required for the policy to be enacted or the education required in the move from siloed to integrated practice. The Australian government has both followed and not followed the UK government. While the intention of the Sure Start program in the UK was taken on board in Australia, the real implications of implementing such policy in an environment where such complex state law exists has not been considered. Thus, the assumptions, omissions and contradictions of policy implementation are more apparent. In short, early years' policy reform in relation to integrated practice in Australia is moving in an ad hoc way. 


\section{References}

Author's Own (2010).

Arthur L et al. (2012) Programming and Planning in Early Childhood Settings. 5th ed. Melbourne, Victoria: Cengage Learning.

Bowe R, Ball SJ and Gold A (1992) Reforming Education and Changing Schools: Case Studies in Policy Sociology. London: Routledge.

Burton J and Lyons M (2000) When does an early childhood teacher teach? In: Hayden J (ed.) Landscapes in Early Childhood Education: Cross National Perspectives on Empowerment. New York: Peter Lang, pp. 271-290.

Cheeseman S (2007) Pedagogical silences in early childhood social policy. Contemporary Issues in Early Childhood 8(7): 244-254.

Children's Workforce Development Council (2010) Everyone working together: Setting up multi-agency services. Available from http://www.bromleypartnerships.org/documents/MAW_booklet_March_2010.pd $\mathrm{f}$

Commonwealth of Australia (2009) Investing in the early years - A national early childhood development strategy. Available from http://www.coag.gov.au/node/205

Crown Copyright (2003) Every child matters. Available from https://www.education.gov.uk/publications/eOrderingDownload/CM5860.pdf 
Department of Communities, Disability Services and Seniors, Queensland (2006)

Towards an early years strategy. Brisbane: Queensland Government.

Department of Education, Employment and Workplace Relations (DEEWR) (2009a)

Supporting the development of young children in Australia: 2009: A snapshot.

ACT: Australian Government. Available from

http://foi.deewr.gov.au/documents/supporting-development-young-childrenaustralia-2009-snapshot

Department of Education, Employment and Workplace Relations (DEEWR) (2009b) The national early childhood reform agenda. ACT: Australian Government. Available from http://www.workforce.org.au/media/38987/deewr\%20big\%20picture\%20present ation\%2015\%20september\%202009.pdf

Department of Education and Training (DET) (2008) Toward Q2: Tomorrow's Queensland. Brisbane: Queensland Government. Available from http://rti.cabinet.qld.gov.au/documents/2008/sep/toward\%20q2/attachments/To wards\%20Q2_\%20Tomorrows\%20Queensland.pdf

Department of Employment, Education and Training (2011) Early childhood education and care workforce action plan. Available from http://deta.qld.gov.au/earlychildhood/pdfs/workforce-action-plan.pdf 
Department of Families, Communities and Indigenous Affairs (2004) Stronger families and communities strategy. ACT: Australian Government.

Department of Families, Housing, Community Services and Indigenous Affairs (2009) Available from http://www.fahcsia.gov.au/sa/families/progserv/familysupport/Pages/default.asp $\mathrm{x} \# 4$

Elliot A (2006) Early childhood education: Pathways to quality and equity for all children. Australian Council for Educational Research. Victoria, Australia: ACER Press.

Elwick S (2010) A philosophical exploration of the complexity of perspective: Possibilities for understanding infants thoughts and perspectives in family day care. Paper presented at the Australian Association of Research in Education Conference Making a Difference, Melbourne, Australia, 28 November - 2 December 2010.

Foucault M (1980) Truth and power. In: Gordon C (ed.) Power/Knowledge: Selected Interviews and Other Writings, 1972-77. New York: Pantheon Books, pp. 109133.

Foucault M (1981) Questions of method: An interview with Michel Foucault. Ideology and Consciousness 8: 3-14. 
Foucault M (1984) Polemics, politics and problematisations. In: Foucault M and Rabinow P (eds.) Ethics: Subjectivity and Truth. Vol. 1 Essential Works of Foucault 1954-1984. New York: New Press, pp. 111-119.

Grieshaber SJ and Canella GS (eds.) Embracing Identities in Early Childhood Education: Diversity and Possibilities. Early Childhood Education Series. New York \& London: Teachers College Press.

Hutchins T and Sims M (1999) Program Planning for Infants and Toddlers: An Ecological Approach. Sydney, Australia: Prentice Hall.

Moore TG (2008) Rethinking Universal and Targeted Services. CCCH Working Paper 2. Parkville, Victoria: Centre for Community Child Health.

Moore T and Skinner A (2010) Background Paper: An Integrated Approach to Early Childhood Development. Paddington, NSW: The Benevolent Society. Available from http://www.rch.org.au/uploadedFiles/Main/Content/ccch/TM_BenSoc_Project_0 9.pdf

Moss P (2006) Farewell to Childcare? National Institute Economic Review 195(1): 7083. Mustard J (2001) Early childhood development and the brain - The base for health, learning and behaviour through life. In: Young ME (ed.) Investing in our 
Children's Future: From Early Child Development to Human Development.

Organisation for Economic Cooperation and Development (OECD) (2006) Starting Strong II: Early Childhood Education and Care. OECD Publishing. Available from http://www.oecd.org/newsroom/37425999.pdf

Petrie A (1988) Education and care: The false dichotomy. Australian Journal of Early Childhood 13(36): 26-30.

Popkewitz T and Lindblad S (2000) Educational governance and social inclusion and exclusion: Some conceptual difficulties and problematics in policy and research. Discourse: Studies in the Cultural Politics of Education 21(1): 5-44.

Press F and Woodrow C (2005) Commodification, corporatisation and children's spaces. Australian Journal of Education 49(3): 278- 2.

Raban B et al. (2006) Statewide Evaluation of Best Start: Final Report. Report prepared for the Victorian Government's Department of Human Services and the Department of Education and Training.

Rudd K and Maklin J (2007). New Directions for Early Childhood Education: Universal Access to Early Learning for 4 Year Olds. Australian Labor Party Policy. Available from http://www.alp.org.au

Sims M (2010) Re-envisaging early childhood teaching. Every Child 16(1): 6-7. 